as she had been given luminal on a previous occasion with no effect one could not put down her improvement to this drug. Before she had the last two treatments she confessed to a great dread of her mother, who was due for a visit lasting ten days, and whose presence on previous occasions had precipitated more acute attacks. Suggestions countering this state of mind were given on the last two occasions, with the result that at the end of the ten days she asked her mother to stay for a further two weeks, and complete harmony reigned throughout the visit. Nine months have elapsed since her last treatment, and she has remained quite well in every respect.

\section{Treatment of Pneumonia}

Dr. R. LaRKIN (London, S.E.1) writes: It is impossible to believe that the figures given in the leading article in the Journal of January 29 (p. 235) for the mortality rates for pneumonia, in this country as compared with America, are correct. If they are correct, and two out of every three pneumonia patients die in England and Wales to one out of every six in America, then it is time the profession learnt to rely on drug therapy instead of on antipneumococcal sera, oxygen, etc. I remember a doctor from Africa saying in the columns of the Journal that he found quinine excellent-so do I in Southwark. Here are the prescriptions I am constantly using -disregarding the possibility of tinct. camph. co. being precipitated as benzoic acid-and in practice I find it is nearly always effective in all types of pneumonia, except, of course, in bronchopneumonia:

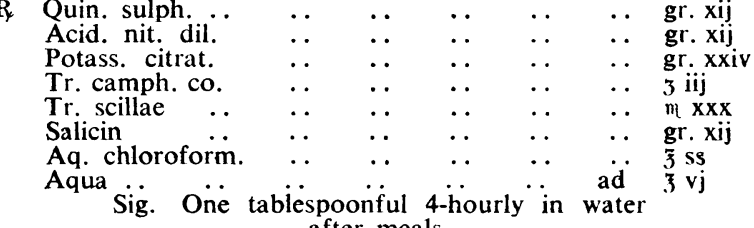

$$
\begin{aligned}
& \text { after meals. }
\end{aligned}
$$

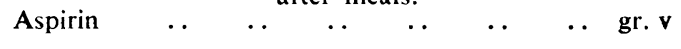

$$
\begin{aligned}
& \left\{\begin{array}{lllllll}
\text { Phenacetin } \ldots & \ldots & \ldots & \ldots & \ldots & \ldots & \text { gr. iv } \\
\text { Caffein citrate } & \ldots & \ldots & \ldots & . & \ldots & \text { gr. i }
\end{array}\right. \\
& \text { Mitte } 6 \text {. One half-tablet of each every four hours }
\end{aligned}
$$

If there is any associated bronchial catarrh, it is convenient to add vin. ipecac. and tinct. senega in small doses. If on academic grounds the incompatibility of the tr. camph. co. is objected to, a way out for the inclusion of the drug in treatment would be to give it in the form of linct. scill. opiat. (B.P.C.) for the associated cough, for $I$ believe it is essential.

\section{Sex Hormone Therapy}

Bayer Products, Limited, have just issued a booklet entitled "Sex Hormone Theory in Everyday Practice," which is a handy guide to those wanting easily available information in this difficult field of practice. In twenty-five pages seven chapters are devoted to the menstrual cycle, the cause of menstrual bleeding, treatment of menstrual disorders, treatment of disorders of pregnancy, endocrinology of the mammary glands, treatment of male disorders, and oestrin and cancer respectively. Then follows a list of Bayer hormone preparations and indications for treatment. The booklet can be obtained free on application to Bayer Products Ltd., Africa House, Kingsway, London, W.C.2.

\section{A Medical Shorthand Writer}

A familiar figure at meetings of medical societies has passed away in the person of Henry Dickinson, official shorthand writer to the Royal Society of Medicine, the Royal MedicoPsychological Association, the Royal Society of Tropical Medicine and Hygiene, the Medical Society of London, the Ophthalmological Society, the Hunterian Society, the Medico-Legal Society, and many other bodies. About forty years ago, a Pitman enthusiast, Dickinson eschewed a wider field for the employment of his flying pencil (or, rather, his pen, for the pencil he scorned as an unworthy tool) and specialized in the reporting of medical proceedings. It was a narrow line, but he cultivated it assiduously, and, in his prime, medical men would swear by "Dickinson's note." If a speaker had a suspicion that he had not said exactly what was attributed to him, such a suspicion was completely dispelled by the production of those copperplate pages. There it was, in thick strokes and thin. His longest tenure was his reportership of the Medical Society of London, which went back for thirty-nine years. He was reporter for several of the bodies which amalgamated in
1907 to form the Royal Society of Medicine, and he remained reporter for that body until his death. Many years ago he published a small manual entitled Medical Reporting in Pitman's Shorthand, in which he gave the shorthand forms for between three and four thousand medical words and phrases, along with some good advice to those who record medical discussions or act as doctors' amanuenses. The student of the published proceedings of various medical societies in years to come, while he will probably never learn the name of the scribe who: set them down in clear and orderly form, will have occasion to be grateful for his patient and skilful work.

\section{Austrian Medical Stamps}

Medical stamps are becoming slowly but increasingly popular in different countries. On December 5, her annual "Day of the Stamp," Austria issued an attractive set of nine stamps commemorating her most distinguished medical sons. The likenesses are extremely good, the portraits being effectively set against a dark background. Van Swieten is depicted in the sepia 5 groschen stamp, Auenbrugger on the red 8, and Rokitansky on the grey 12. Skoda looks characteristically pedantic and dull on the green 20 stamp, while Hebra's appearance on the violet 24 is that of a genial bon-vivant. The carmine 30 represents von Arlt and the violet-red 64 Theodor Meynert. Perhaps the most striking portraits are those of Joseph Hyrtl, the anatomist (olive green 40), and of Billroth (blue 60).

\section{Magnifiers in Spectacle Frames}

Dr. A. J. Ballantyne (Glasgow) writes: Dr. F. Oliver Walker's short communication in the Journal of February 12 (p. 339) was of interest to me as I have had magnifiers of very similar construction in use for many years. The arrangement was suggested to me by a one-eyed patient, who had fitted a skeleton watchmaker's glass by fixing it to his own spectacle frame. Taking his hint. I got Messrs. John Trotter Ltd., opticians in Glasgow, to make a similar fitting for trial. Since then many patients have used this contrivance with satisfaction. These have mostly been cases of amblyopia, where magnification enabled the patient to read. The lens of the watchmaker's fitting can be made of any convenient strength, and the arrangement has the advantage that, being worn as a spectacle frame, both hands are available for holding a book, and as the watchmaker's fitting folds up the spectacles go into an ordinary flat case.

\section{Medical Books for Surgeons in Spain}

The Organizing Secretary of the Spanish Medical Aid Committee (24, New Oxford Street, W.C.1) writes: I have received a request from Spain for the Annals of Surgery, 1937 (published by John Wright and Sons Ltd., Bristol), and Surgery, Gynecology and Obstetrics, 1937 (published by Baillière, Tindall and Cox). We are anxious to send these out to the surgeons who require them, but are equally anxious not to draw on our funds for this purpose if it can possibly be avoided, and we wonder, therefore, whether any of your readers would be prepared to send us these for use in Spain.

\section{Albuminuria and Bromides}

Dr. S. J. HaYlock (Southbourne-on-Sea) writes: In cases of albuminuria from whatever cause the intake of bromides in medicinal doses tends to aggravate the condition, and to cause skin eruptions, etc. Patients suffering from albuminuria are advised not to take table salt. I would suggest also that no form of bromide be prescribed for them.

\section{Corrigenda}

We are asked to correct an error in the report of the opening of the new premises of the Institute for the Scientific Treatment of Delinquency published at page 416 of our issue for February 19. Dr. E. T. Jensen, chairman of the Institute, in expressing thanks to Lord Roche, said that he envisaged "an international Institute of Criminology," not "a large national" one.

In the Analysis of Cases of Sympathetic Ophthalmia from Schools for Blind Children published last week at page 393, in the fifth line of the second column "ophthalmia neonatorum", should of course have been "sympathetic ophthalmia."

The date in the first line of the second paragraph of the description of Case 1 in Dr. R. Stuart Renton's letter in the Journal of February 19 (p. 422) should be December 17 and not December 7 as printed. 